\title{
Evaluation of Some Inflammatory Biomarkers and Environmental Predictors in Children with Acute Lymphoblastic Leukemia
}

\author{
Mai Sabry Saleh ${ }^{1 *}$, Dina Bassiouny ${ }^{2}$, Asmaa Fathi Galal ${ }^{3}$, Eman Essam Shaban ${ }^{1}$ and Zeinb Mohamed \\ Monir $^{4}$ \\ ${ }^{1}$ Environmental and Occupational Medicine Department, Environmental Research Division, National Research Centre, Egypt \\ ${ }^{2}$ Pediatric Oncology Department, National Cancer Institute, Egypt
}

${ }^{3}$ Narcotics, Ergogenics and Poisons department, Medical Research Division, National Research Centre, Egypt

${ }^{4}$ Child Health Department, National Research Centre, Medical Research Division, National Research Centre, Egypt

\begin{abstract}
Acute Lymphoblastic Leukemia in children became a public health concern due to great progress in cure rates. Inflammation plays a crucial role in disease induction and progression as well as in response to treatment. The aim of the present work is to screen the inflammatory status in a cohort of pediatric patients with ALL and to define any treatment or socio-demographic variables related to its aggravation. The study included 79 cases of pediatric cancer patients diagnosed with ALL at the out-patient clinic of the National Cancer Institute in Egypt. Participants responded with their parents to complete the designed questionnaire and a blood sample was taken for assessment of cortisol, C-reactive protein, serum alpha amylase, triglycerides and total cholesterol using ELISA and colorimetric techniques as applied. The study findings showed prominent decrease in cortisol level with mean value of $119 \mathrm{nmol} / \mathrm{l}$, outstanding rise in CRP that reached the mean value of $84 \mathrm{mg} / \mathrm{L}$ and elevated level of triglycerides (183 mg/dl). The significant decrease in cortisol was found accompanying higher compliance to treatment, increased hospitalization and early stages of treatment Total cholesterol and alpha amylase showed to be within normal ranges (185 mg/dl and $26 \mathrm{U} / \mathrm{L}$, respectively). As a conclusion, ALL pediatric cancer patients could be suffering from chronic stress that is attributed to both the disease manifestations and treatment procedures. The increased CRP level could be a consequence of the low cortisol level and could be disease and/or treatment related.
\end{abstract}

KEYWORDS: Acute lymphoblastic leukemia; Stress; Inflammation childhood cancer; Cortisol; CRP

\section{INTRODUCTION}

Childhood cancer is a subject of growing concern worldwide, and especially in developing countries, due to increasing rate of incidence. Subsequent morbidities and mortalities due to cancer reached about 100,000 child under the age of fifteen per year in such countries [1]. In the Arab region, specifically, incidence rate keeps growing [2] including Egypt where 70\% of childhood cancer patients die every year with incidence of $9.4 \%$ for children under the age of 20 years old [3]. Acute Lymphoblastic Leukemia (ALL), in particular, is the most abundant type of childhood cancer that is characterized with very good prognosis and high cure rates ranging between $75 \%$ and $85 \%$ [4].
Quick Response Code:

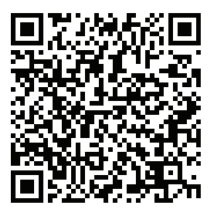

Address for correspondence: Mai Sabry Saleh, Environmental and Occupational Medicine Department, Environmental Research Division, National Research Centre, Egypt

Received: July 26, 2021 Published: July 30, 2021

How to cite this article: Mai Sabry S, Dina B, Asmaa FG, Eman ES, Zeinb MM. Evaluation of Some Inflammatory Biomarkers and Environmental Predictors in Children with Acute Lymphoblastic Leukemia. 2021- 3(4) OAJBS.ID.000312. DOI: 10.38125/OAJBS.000312 
In the last couple of decades enormous interest has been evolving about the contribution of inflammation to cancer in its development and progression at one side and therapy at another side. Inflammation has been found to exist long before tumor formation and this helps in promotion of cancer induction. The pro-tumorigenic inflammation acts on blocking the anti-tumor immunity with subsequent shaping of the Tumor Microenvironment in the direction of more tumor-permissive state. In addition, inflammation exerts direct tumor-promoting signals that results in production of cancer cells. Many mechanisms of inflammation has also been suggested to affect tumor progression and metastasis [5].

Inflammation can also develop in cancer patients in response to the different types of anti-cancer therapies; chemotherapy and radiotherapy. This is normally the result of partial destruction of tumors with release of dead cell material that stimulate an inflammatory response resembling injury to normal tissue [5]. Unfortunately, ALL patients suffer from physical changes (hair loss, pain, repeated hospitalization, weight gain and aggressive treatment procedures) that affect their mental, physical and emotional state [6]. Such manifestations of stress increase inflammatory biomarkers and can adversely affect patients at the different stages of their treatment that could last for years.

On physiological basis, the hypothalamic-pituitary-adrenal (HPA) axis increased activity regulates the release and production of the inflammatory biomarkers. One of the key role players is cortisol hormone that is secreted by the HPA axis in response to acute and prolonged stress. Cortisol is commonly viewed as a biomarker for indexing HPA axis activity especially in children [7]. C-reactive protein (CRP) is another inflammatory biomarker that is associated with cancer and is considered as a prognostic marker in many of its types [8]. Serum alpha amylase is another biomarker that accompany many inflammatory complications associating tumor progression and treatment adverse effects.

The present study is aiming at screening levels of inflammatory biomarkers; cortisol, C-reactive protein, serum alpha amylase and lipid profile in ALL patients and investigating some of the socio-demographic and treatment related procedures that could negatively affect the inflammatory status among children with ALL with consequent decline in treatment outcomes and/or general wellbeing during the long treatment journey.

\section{METHODS}

This work is a screening cross sectional study that was carried on pediatric patients treated at the National Cancer Institute (NCI) outpatient clinic and diagnosed with Acute Lymphoblastic Leukemia (ALL) at different stages of treatment/follow up. Recruitment period continued for 4 months. Total cases included in the study reached 79 cases. (25 under treatment, 39 follow up, 2 on palliation and 13 missing). Ethical approval was provided by the ethical committee at the National Research of Egypt and all participants orally agreed to be part of the study.

Socio-demographic (age, gender \& residence) and treatment related data (Hospitalization; admission period as inpatient per month, Frequency; number of visits per month, Duration; total period of treatment and Compliance; degree of commitment to treatment protocol) were collected from parents of patients.

Blood samples $(3 \mathrm{ml})$ were collected in plain tubes at the early morning from fasting patients, centrifuged at $3000 \mathrm{rpm}$ then stored at -20 degrees for further detection of biomarkers.
Cortisol hormone was detected using ELISA kit purchased from AB Diagnostic Systems GmbH Germany. Serum C-reactive protein (CRP) was measured using ELISA kit (Monocent, Inc, USA). Triglycerides (TG) and total cholesterol (TC) were measured using colorimetric kits according to manufacturer's instructions (MG, Science \& Technology Center, Egypt). Alpha amylase ( $\alpha$-amylase) activity in serum was measured using commercial kits according to manufacturer's instructions (Spectrum, Egypt).

Statistical analyses were performed using IBM SPSS Statistics 22.0 for descriptive; means with standard deviation for continuous data and frequency distribution for the categorical, and comparative tests; student $t$ test.

\section{RESULTS}

In the present study, males are exceeding females, most of the population are coming from rural residence, diagnosed at an age above 5 years, highly compliant to treatment protocol with admission for more than half the treatment period, showing low frequency of hospital visits and have completed more than 6 months of treatment (Table1).

Table 1: Descriptive data of socio-demographic and treatment variables represented in frequency and percentage.

\begin{tabular}{|c|c|}
\hline Study Variables (N) & $\mathbf{N}(\%)$ \\
\hline \multicolumn{2}{|c|}{ Age at Diagnosis (62) } \\
\hline$\leq 5$ & $17(21)$ \\
\hline$>5$ & $45(54)$ \\
\hline \multicolumn{2}{|c|}{ Gender (79) } \\
\hline Male & $51(61)$ \\
\hline Female & $28(34)$ \\
\hline \multicolumn{2}{|c|}{ Residence (75) } \\
\hline Urban & $29(35)$ \\
\hline Rural & $46(55)$ \\
\hline \multicolumn{2}{|c|}{ Frequency of Visits (76) } \\
\hline$<$ Once/Month & $59(71)$ \\
\hline 1to 3 Times/Month & $15(18)$ \\
\hline$>3$ Times/Month & $2(2)$ \\
\hline \multicolumn{2}{|c|}{ Hospital Admission (77) } \\
\hline$<$ Half Treatment Period & $2(2)$ \\
\hline Half Treatment Period & $74(89)$ \\
\hline >Half Treatment Period & $1(1)$ \\
\hline \multicolumn{2}{|c|}{ Duration of Treatment (75) } \\
\hline$<3$ Months & $17(21)$ \\
\hline 3 to 6 Months & $5(6)$ \\
\hline$>6$ Months & $58(70)$ \\
\hline \multicolumn{2}{|c|}{ Compliance (76) } \\
\hline Poor & $3(4)$ \\
\hline Moderate & $32(39)$ \\
\hline Good & $41(49)$ \\
\hline
\end{tabular}


Table 2: Descriptive data of age at the time of the study and the estimated biomarkers represented in mean and standard deviation (Mean \pm SD).

\begin{tabular}{|c|c|c|c|}
\hline Parameter (N) & Mean \pm SD & Minimum & Maximum \\
\hline Age (76) & $11 \pm 3$ & 7 & 23 \\
\hline Age at diagnosis (62) & $7 \pm 2$ & 1 & 10 \\
\hline CRP (mg/L) (44) & $84 \pm 77$ & 11 & 1499 \\
\hline Triglyceride (mg/dl) (51) & $183 \pm 211$ & 17 & 465 \\
\hline Total Cholesterol (mg/dl) (46) & $185 \pm 91$ & 2 & 67 \\
\hline$\alpha$-amylase (U/L) (49) & $26 \pm 17$ & 15 & 30 \\
\hline BMI (52) & $19 \pm 3$ & 10 & 528 \\
\hline Cortisol (nmol/l) (73) & 11999 & & \\
\hline
\end{tabular}

Table 3: Compared mean levels of the assessed biomarkers in terms of some socio-demographic variables; age at diagnosis, gender and residence.

\begin{tabular}{|c|c|c|c|c|c|c|}
\hline \multirow{2}{*}{} & \multicolumn{2}{|c|}{ Age at Diagnosis } & \multicolumn{2}{c|}{ Gender } & \multicolumn{2}{c|}{ Residence } \\
\cline { 2 - 7 } & $>\mathbf{1},<\mathbf{1 0} \mathbf{y}$ & $\leq \mathbf{1 ,} \geq \mathbf{1 0} \mathbf{y}$ & Male & Female & Urban & Rural \\
\cline { 2 - 7 } & Mean $\pm \mathbf{S D}(\mathbf{N})$ & Mean $\pm \mathbf{S D}(\mathbf{N})$ & Mean $\pm \mathbf{S D}(\mathbf{N})$ & Mean \pm SD(N) & Mean \pm SD(N) & Mean $\pm \mathbf{S D}(\mathbf{N})$ \\
\hline Age & - & - & $11 \pm 3(47)$ & $12 \pm 4(26)$ & $11 \pm 3(29)$ & $11 \pm 3(46)$ \\
\hline CRP (mg/L) & $79 \pm 71(34)$ & $86 \pm 82(6)$ & $81 \pm 78(29)$ & $88 \pm 77(15)$ & $90 \pm 79(18)$ & $85 \pm 77(24)$ \\
\hline Triglyceride (mg/dl) & $195 \pm 237(39)$ & $164 \pm 96(7)$ & $206 \pm 253(33)$ & $140 \pm 88(18)$ & $153 \pm 83(21)$ & $193 \pm 273(28)$ \\
\hline Total Cholesterol (mg/dl) & $178 \pm 93(36)$ & $227 \pm 102(6)$ & $194 \pm 90(31)$ & $166 \pm 94(15)$ & $205 \pm 88(19)$ & $167 \pm 95(25)$ \\
\hline$\alpha$-amylase (U/L) & $27 \pm 16(38)$ & $25 \pm 24(7)$ & $25 \pm 14(32)$ & $28 \pm 21(17)$ & $29 \pm 16(20)$ & $26 \pm 17(27)$ \\
\hline BMI & $19 \pm 3(40)$ & $20 \pm 4(5)$ & $19 \pm 4(33)$ & $20 \pm 3(18)$ & $19 \pm 4(23)$ & $19 \pm 3(28)$ \\
\hline Cortisol (nmol/l) & $137 \pm 110 *(50)$ & $77 \pm 55^{*}(9)$ & $128 \pm 113(45)$ & $102 \pm 67(27)$ & $146 \pm 117(25)$ & $112 \pm 88(41)$ \\
\hline
\end{tabular}

Table 4: Compared mean levels of the assessed biomarkers in terms of some treatment related variables; frequency of hospital visits, hospitalization, total treatment duration and compliance to treatment.

\begin{tabular}{|c|c|c|c|c|c|c|c|c|c|c|c|c|}
\hline & \multicolumn{3}{|c|}{$\begin{array}{l}\text { Frequency of Hospital } \\
\text { Visits (Times Per Month) }\end{array}$} & \multicolumn{3}{|c|}{$\begin{array}{c}\text { Hospital Admission (In } \\
\text { Terms of Treatment } \\
\text { Period) }\end{array}$} & \multicolumn{3}{|c|}{$\begin{array}{c}\text { Duration of Treatment (In } \\
\text { Months) }\end{array}$} & \multicolumn{3}{|c|}{ Compliance } \\
\hline & < once & $1-3$ & $>3$ & $<$ half & Half & $>$ half & $<3$ & 3 to 6 & $>6$ & Poor & Moderate & Good \\
\hline & $\begin{array}{c}\text { Mean } \\
\pm \text { SD (N) }\end{array}$ & $\begin{array}{c}\text { Mean } \\
\pm \text { SD (N) }\end{array}$ & $\begin{array}{c}\text { Mean } \\
\pm \text { SD (N) }\end{array}$ & $\begin{array}{c}\text { Mean } \\
\pm \text { SD (N) }\end{array}$ & $\begin{array}{c}\text { Mean } \\
\pm \text { SD (N) }\end{array}$ & $\begin{array}{c}\text { Mean } \\
\pm \text { SD (N) }\end{array}$ & $\begin{array}{c}\text { Mean } \\
\pm \text { SD (N) }\end{array}$ & $\begin{array}{c}\text { Mean } \\
\pm S D(N)\end{array}$ & $\begin{array}{c}\text { Mean } \\
\pm \text { SD (N) }\end{array}$ & $\begin{array}{c}\text { Mean } \\
\pm \text { SD (N) }\end{array}$ & $\begin{array}{c}\text { Mean } \\
\pm \text { SD (N) }\end{array}$ & $\begin{array}{c}\text { Mean } \\
\pm \text { SD (N) }\end{array}$ \\
\hline \multirow{2}{*}{ Age } & $12 \pm 3$ & $11 \pm 4$ & $10 \pm 1$ & $10 \pm 2$ & $11 \pm 3$ & $10 \pm 0$ & $11 \pm 3$ & $9 \pm 1$ & $12 \pm 3$ & $11 \pm 1$ & $10 \pm 1^{*}$ & $13 \pm 4^{*}$ \\
\hline & (58) & (15) & (2) & (2) & (73) & (1) & (12) & (5) & (56) & (3) & (32) & $(40)$ \\
\hline \multirow{2}{*}{$\begin{array}{c}\mathrm{CRP} \\
(\mathrm{mg} / \mathrm{L})\end{array}$} & $93 \pm 84^{*}$ & $72 \pm 58$ & $40 \pm 3^{*}$ & $95 \pm 119$ & $85 \pm 77$ & 86 & $73 \pm 85$ & $57 \pm 69$ & $89 \pm 79$ & $116 \pm 128$ & $94 \pm 82$ & $67 \pm 63$ \\
\hline & $(30)$ & (11) & (2) & (2) & $(40)$ & (1) & (6) & (5) & (30) & (2) & (26) & (15) \\
\hline \multirow{2}{*}{$\begin{array}{l}\text { Triglyc- } \\
\text { erides } \\
\text { (mg/dl) }\end{array}$} & $\begin{array}{c}190 \\
\pm 244\end{array}$ & $\begin{array}{c}166 \\
\pm 104\end{array}$ & $65 \pm 33$ & $92 \pm 56$ & $\begin{array}{c}186 \\
\pm 216\end{array}$ & 11 & $122 \pm 58$ & $140 \pm 57$ & $195 \pm 248$ & $129 \pm 19$ & $150 \pm 102$ & $\begin{array}{c}234 \\
\pm 327\end{array}$ \\
\hline & (35) & (13) & (2) & (2) & $(47)$ & (1) & (8) & (5) & (35) & (3) & (29) & (18) \\
\hline \multirow{2}{*}{$\begin{array}{c}\text { Total } \\
\text { chole- } \\
\text { sterol } \\
(\mathrm{mg} / \mathrm{dl})\end{array}$} & $\begin{array}{l}195 \\
\pm 91\end{array}$ & $173 \pm 98$ & $102 \pm 35$ & $184 \pm 16$ & $188 \pm 94$ & 82 & $\begin{array}{c}159 \\
\pm 111\end{array}$ & $156 \pm 57$ & $196 \pm 94$ & $143 \pm 44$ & $190 \pm 90$ & $\begin{array}{c}185 \\
\pm 107\end{array}$ \\
\hline & (32) & (11) & (2) & (2) & $(42)$ & (1) & (7) & (5) & (32) & (3) & (29) & (13) \\
\hline \multirow{2}{*}{$\begin{array}{c}\alpha \text {-amy- } \\
\text { lase } \\
(\mathrm{U} / \mathrm{L})\end{array}$} & $24 \pm 16$ & $30 \pm 16$ & $44 \pm 8$ & $43 \pm 9$ & $26 \pm 16$ & 5 & $35 \pm 18$ & $36 \pm 10$ & $24 \pm 16$ & $15 \pm 18$ & $26 \pm 14$ & $29 \pm 20$ \\
\hline & (33) & (13) & (2) & (2) & $(45)$ & (1) & (8) & (4) & (34) & (2) & (29) & (17) \\
\hline \multirow{2}{*}{ BMI } & $19 \pm 4$ & $19 \pm 3$ & $18 \pm 3$ & $18 \pm 2$ & $19 \pm 3^{*}$ & $26^{*}$ & $18 \pm 2$ & $18 \pm 3$ & $19 \pm 4$ & $18 \pm 5$ & $18 \pm 3^{*}$ & $20 \pm 3^{*}$ \\
\hline & (34) & (15) & (2) & (2) & (49) & (1) & (8) & (5) & (36) & (3) & (31) & (17) \\
\hline \multirow{2}{*}{$\begin{array}{l}\text { Cortisol } \\
\text { (nmol/l) }\end{array}$} & $124 \pm 102$ & $132 \pm 99$ & $72 \pm 38$ & $261 \pm 89 *$ & $120 \pm 98^{*}$ & 140 & $76 \pm 54 * \circ$ & $\begin{array}{r}215 \\
\pm 109^{\circ}\end{array}$ & $\begin{array}{c}128 \\
\pm 103^{*}\end{array}$ & $274 \pm 43^{*}$ & $177 \pm 116^{\circ}$ & $73 \pm 38 * \circ$ \\
\hline & (51) & (15) & (2) & (2) & $(65)$ & (1) & (12) & (5) & (49) & (2) & (30) & $(36)$ \\
\hline
\end{tabular}


Table 2 shows that patients at the time of the study aged between seven and twenty-three years old, with 11 years as mean value. Means of the biochemical measures for all participants with minimum and maximum values are also illustrated. The CRP mean value shows to be very much higher in its level than the normal range $(0.2-10 \mathrm{mg} / \mathrm{L})$ in all participants without any significant difference between groups classified after their socio-demographics (Table 3). Yet CRP was significantly higher in cases with less hospitalization (Table 4).

Regarding cortisol, it shows mean value among all ALL patients (119 $\mathrm{nmol} / \mathrm{l})$ that is less than the lower normal limit (138-690 nmol/l); (Table 2). Cortisol levels also shows significant decrease at the early stages of treatment, among the highly compliant group and in accompany with longer periods of hospitalization (Table 4). Triglycerides normal ranges are known to be $40-160 \mathrm{mg} / \mathrm{dl}$ for males and $35-135 \mathrm{mg} / \mathrm{dl}$ in females. According to the estimated levels the mean value for all participants exceeded the upper limit (Table 2). On the other hand, Total Cholesterol and alpha amylase showed to be at the normal level for all study groups. Mean values for BMI were also within the normal range yet it significantly increases in cases of long periods of hospitalization and high compliance to treatment to above the value of 20 .

\section{DISCUSSION}

The present work is witnessing a dramatic drop in cortisol levels in children with Acute Lymphoblastic Leukemia (ALL) which agrees with similar studies [9]. This decreased level could have many indications. Firstly, it could be due to chemotherapy which justifies the significantly lower levels $(76 \mathrm{nmol} / \mathrm{l})$ in patients at their first three months of treatment through which they are subjected to aggressive chemotherapy for induction of remission [10]. Secondly, it is a reflection of how the body is coping with stressful situations that are associating treatment procedures. The lower cortisol levels help patients in reacting to stressful stimuli with less intensity and this could explain the significant extreme lower level in case of patients reporting high rate of compliance to treatment $(73 \mathrm{nmol} / \mathrm{l})$ and those with excessive hospitalization [11].

According to literature, glucocorticoids suppress inflammation with the ability to inhibit the genetic expression of pro-inflammatory cytokine [12]. This could explain the uncontrolled elevation in CRP levels in all the study sample who witness very low cortisol levels. In a similar study, CRP level was detected to range from 0 to $35 \mathrm{mg} / \mathrm{L}$ among ALL patients irrespective of tumor type or treatment stage with levels exceeding $40 \mathrm{mg} / \mathrm{L}$ in cases of bacterial infection [13]. These could represent other justifications for the extremely elevation in CRP. CRP has also been reported to increase at diagnostic stages of malignancies where it ranged between $>5$ and $211 \mathrm{mg} / \mathrm{L}$ in pediatrics with Hodgkin Disease. Despite being a nonspecific inflammatory biomarker, yet CRP is a prognostic biomarker in tumors that is associated with increased incidence of relapse [8].

TG levels in the present study showed mean value exceeding the upper normal limit which is another sign of increased inflammatory signs at the time where cholesterol and BMI showed to be within normal ranges. These results typically agree with current research findings $[14,15]$. Some studies attribute such disturbances to be restricted to the time of diagnosis with ALL, accompanying therapy containing L-asparaginase or due to altered lipid metabolism or nutritional states [16]. Yet an overall conclusion is suggesting lipid profile monitoring as diagnostic/prognostic measure for in management of ALL with an emerging concept that TG are higher during therapy and lowers down but the end of treatment regimens while the case is reversed for cholesterol [14]. According to Mandal [17] $\alpha$-amylase enzyme activity in human serum is an indicator of onset in many inflammatory conditions including cancer and stress. It is normally linked with acute stress and that is why it showed to be within the normal range in all study participants.

Age at diagnosis is an important prognostic factor in pediatric cancers and especially ALL. Better cure rates have been reported for diagnosis at the ages of 1 and 9 . In the current study the group with bad prognosis (less than one year and more than 9 years at diagnosis) showed significant lower level of cortisol which ensures the low prognosis and invites special care for such category. Girls with ALL also report better cure rates than boys, yet their inflammatory biomarkers didn't show any significant difference and unfortunately proved uncontrolled inflammatory condition that is further evidenced by increased levels of CRP and decreased levels of cortisol below normal [18].

\section{CONCLUSION}

In conclusion, it is clear that pediatric patients with ALL are suffering from chronic stress with levels below lower limits and consequent uncontrolled elevation in CRP. Both findings represent serious risk factors. Despite such a situation could be acceptable for those under treatment, yet the study sample includes follow up cases and others who achieved remission. As a recommendation, cancer patient from children with ALL need special psychological and social care for better coping with the great challenges that they face both due to the disease and treatment aggressiveness. Identifying challenges at each stage of disease/treatment need to be studied through longitudinal research with larger sample size.

\section{FUNDING}

The present work is funded by the National Research Center through project number 120801.

\section{ETHICAL APPROVAL}

The present work is done after permission from the ethical committee of the National Research Centre.

\section{REFERENCES}

1. Ferlay J, Shin HR, Bray F, Forman D, Mathers C, et al. (2010) Estimates of worldwide burden of cancer in 2008: GLOBOCAN 2008. Int J Cancer 127: 2893-2917.

2. Salim EI, Moore MA, Al Lawati JA, Al Sayyad J, Bawazir A, et al. (2009) Cancer epidemiology and control in the arab world - past, present and future. Asian Pacific J Cancer Prev 10(1): 3-16.

3. Malla ELH (2017) Having a child diagnosed with cancer: Raising the challenges encountered by the caregivers at the pediatric oncology ward in Egypt. Diseases 5(4): 36.

4. Ramaneswaran S, Srinivasan K, Durai RVPM, Chang CY (2021) Hybrid inception v3 XGBoost Model for acute lymphoblastic leukemia classification computational and mathematical. Methods in Medicine. Article ID 2577375: 1-10.

5. Greten FR, Grivennikov SI (2019) Inflammation and cancer: Triggers, mechanisms, and consequences. Immunity 51(1): 27-41.

6. Adler NE, Page AEK (2008) Cancer care for the whole patient: Meeting psychosocial health needs. Institute of Medicine (IOM). Washington DC: National Academies Press.

7. Gunnar M, Quevedo K (2007) The neurobiology of stress and development. Annu Rev Psychol 58: 145-173. 
8. Wieland A, Kerbl R, Berghold A, Schwinger W, Mann G, et al. (2003) C-reactive protein (CRP) as tumor marker in pediatric and adolescent patients with Hodgkin disease. Med Pediatr Oncol 41(1): 21-25.

9. Firoozi M, Besharat MA (2013) Cortisol-a key factor to the understanding of the adjustment to childhood cancer. Iranian J Cancer Prev 6(1): 1-7.

10. Hanna JRA (2015) Expression of CD95 in acute lymphocytic leukemia (ALL) in Egyptian children before and after Treatment. J Blood Disorders Transf 6: 250.

11. Williams NA, Davis G, Hancock M, Phipps S (2010) Optimism and pessimism in children with cancer and healthy children: Confirmatory factor analysis of the youth life orientation test and relations with health-related quality of life. Pediatr Psychol 35: 672- 682.

12. Griffin JE, Ojeda SR (2000) Textbook of endocine physiology. Oxford University Press, USA, pp. 334-346.
13. Santolaya ME, Cofre J, Beresi V (1994) C-reactive protein: A valuable aid for the management of febrile children with cancer and neutropenia. Clin Infect Dis 18(4): 589-595.

14. Usman H, Rashid R, Ameer F, Iqbal A, Zaid M, et al. (2015) Revisiting the dyslipidemia associated with acute leukemia. Clin Chim Acta 15: 4444344449.

15. Kuliszkiewicz JM, Małecki R, Mohamed AS (2008) Lipid changes occuring in the course of hematological cancers. Cell Mol Biol Lett 13(3): 465-474

16. Halton JM, Nazir DJ, McQueen MJ, Barr RD (1998) Blood lipid profiles in children with acute lymphoblastic leukemia. Cancer 83(2): 379-384.

17. Mandal N, Bhattacharjee M, Chattopadhyay A, Bandyopadhyay D (2019) Point-of-care-testing of $\alpha$-amylase activity in human blood serum. Biosens Bioelectron 15: pp.124-125:75-81.

18. The American Cancer Society medical and editorial content team. 